\title{
Vibrational and Electronic Spectra of Natural Dyes Constituents for Solar Cell Application: DFT and TDDFT Study
}

\author{
Joseph Makuraza*, Tatiana Pogrebnaya, Alexander Pogrebnoi \\ Dept. of Materials, Energy Science and Engineering, The Nelson Mandela African Institution of Science and Technology, Arusha, Tanzania
}

Email address:

makurazaj@nm-aist.ac.tz (J. Makuraza), tatiana.pogrebnaya@nm-aist.ac.tz (T. Pogrebnaya), pgamtp@mail.ru (A. Pogrebnoi), alexander.pogrebnoi@nm-aist.ac.tz (A. Pogrebnoi)

\section{To cite this article:}

Joseph Makuraza, Tatiana Pogrebnaya, Alexander Pogrebnoi. Vibrational and Electronic Spectra of Natural Dyes Constituents for Solar Cell Application: DFT and TDDFT Study. International Journal of Materials Science and Applications. Vol. 4, No. 5, 2015 , pp. $314-324$. doi: 10.11648/j.ijmsa.20150405.16

\begin{abstract}
Selected constituents of natural dyes, phenol, 1,2-benzoquinone, 1,4-benzoquinone, 1,4-naphthoquinone, and 9,10-anthraquinone have been studied theoretically using the density functional theory and time-dependent density functional theory. The vibrational and electronic spectra have been computed with $6-311++\mathrm{G}(\mathrm{d}, \mathrm{p})$ basis set. It was found that 1,2-benzoquinone, 1,4-naphthoquinone, and 9,10-anthraquinone may satisfy some criteria to become photosensitizer in DSSCs; the absorption bands computed for molecules in vacuum appeared at 396, 348, and $326 \mathrm{~nm}$, respectively. When computed for molecules in solutions using the polarized continuum model, the bands were red-shifted: 446 (1,2-benzoquinone in water), 355 (1,4-naphthoquinone in heptane), and $329 \mathrm{~nm}(9,10$-anthraquinone in heptane). Our results have shown that 1,2-benzoquinone among the others would exhibit better photovoltaic properties in terms of light absorption and energy level alignment.
\end{abstract}

Keywords: Dye Sensitized Solar Cell, Sensitizer, Phenol, Benzoquinone, Naphthoquinone, Antraquinone, Geometrical Parameters, Vibrational Spe, Electronic Spectra

\section{Introduction}

Alternative energy sources and electric energy storage are becoming important for solving issues on pending energy crisis and sustainable use. Photovoltaic solar cell systems are among the alternative energy systems that provide green electrical energy. Solar energy is essentially almost infinite, and freely available; and is directly converted into electrical energy without emitting greenhouse gases. Crystalline silicon solar cells have been extensively studied and used for practical applications, but the materials are expensive and manufacturing costs are high that eventually have resulted in long energy payback times of solar panels.

This makes the development of new molecular materials and nanostructures using organic heterocyclic highly desirable for solar cell applications [1]. A dye-sensitized solar cell (DSSC) was first fabricated by O'Regan and Grätzel [2]. DSSCs are working thanks to organic and inorganic sensitizers. The DSSCs have a high potential to be an alternative to more expensive silicon solar cells because of their reasonable production costs, ease of fabrication, and promising conversion efficiency of sunlight into electricity [3]. Ruthenium-based complexes have shown to be the best sensitizers of high conversion efficiency [4], but the metal is toxic and not abundant, and the synthesis of dyes based on ruthenium is complicated and costly. For these factors more studies are needed to develop organic sensitizers for DSSC. The role of a sensitizer is to absorb light and inject the photo-generated electrons to the conduction band of the nanocrystalline semiconductor $\left(\mathrm{TiO}_{2}, \mathrm{ZnO}, \mathrm{SnO}_{2}\right.$ and others).

To be sensitizers in DSSCs, constituents of natural dyes have to satisfy the following arguments: (i) their intense absorption band in the visible and near-UV region, (ii) the presence of the anchoring groups allowing the bonding to the $\mathrm{TiO}_{2}$ and the charge transfer, and (iii) the good energy level alignment with the conduction band edge of the semiconducting substrate and the redox level of the electrolyte [2, 4, 5].

Recently, Mphande and Pogrebnoi [6] found that the crude natural dyes contain different constituents such as phenols, flavonoids, quinones, coumarins and carotenoids. These 
compounds have several desirable characteristics related to their use in different applications. Quinones are used in production of hydrogen peroxide [7], biochemistry, medicinal [8], dyes, reagents in organic chemistry [9] and battery charge carrier [10]. Theoretical and experimental studies on structural and vibrational spectra of some quinones and its derivatives have been carried out [11-13]. But a few theoretical studies have been done on electronic spectra, and also objectives of authors were not addressing to photosensitizers $[14,15]$.

The objective of this work is to compute vibrational and electronic spectra of phenol, 1,2-benzoquinone (1,2-BQ), 1,4-benzoquinone (1,4-BQ), 1,4-naphthoquinone (1,4-NQ), and 9,10-antraquinone (9,10-AQ) molecules using density functional theory (DFT) and time-dependent density function theory (TDDFT).

\section{Computational Details}

The structural parameters have been optimized for all species. The vibrational spectra have been calculated and all structures were confirmed as true energy minima by the absence of imaginary frequencies. Electronic structure and spectra were computed for species both in vacuum and in solutions using the polarized continuum model (PCM). All computations were carried out using Firefly 8.1.0 [16] which is partially based on the GAMESS (US) source code [17]. The DFT method, the level of B3LYP5/6-31G(d) and B3LYP5/6-311++G(d,p) [18] was applied to compute the geometrical parameters and vibrational spectra. Electronic spectra were calculated using the TD-DFT [19] at the B3LYP/6-311++G(d,p) level. Thermodynamic functions have been calculated using OpenThermo software [20]. The HyperChem [21] software was used to calculate initial coordinates of atoms. The ChemCraft program [22] was applied for visualization of the results of the Firefly output files.

\section{Results and Discussion}

\subsection{Optimized Geometrical Parameters}

The optimization was done for all species using two basis sets: B3LYP5/6-31G(d) and B3LYP5/6-311++G(d,p). There were no contradiction between the parameters found with both basis sets; moreover the difference was not essential. The results obtained with the basis set B3LYP5/6-311++G(d,p) are given hereafter. The optimized geometrical structures of phenol, 1,2-BQ, 1,4-BQ, 1,4-NQ, and 9,10-AQ are shown in Fig. 1. The selected geometrical parameters are listed in Tables 1-3.

Phenol. The optimized bond lengths and bond angles are summarized in Table 1. The bond lengths O1-C2, O1-H8, $\mathrm{C}-\mathrm{H}$ and aromatic $\mathrm{C}-\mathrm{C}$, are equal to $1.371 \AA, 0.963 \AA$, (1.082-1.085) $\AA,(1.390-1.395) \AA$, and valence angle $\mathrm{C} 2-\mathrm{O} 1-\mathrm{H} 8$ is $109.6^{\circ}$ respectively. Bond angles inside and outside benzene ring are all equal to $120.0^{\circ}$, only one angle C2-O1-H8 differs from others and equal to $109.5^{\circ}$.

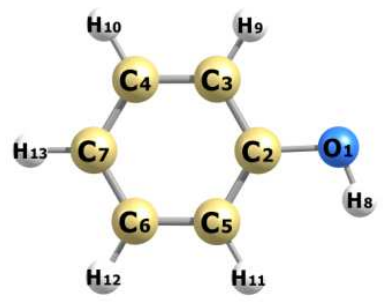

(a)

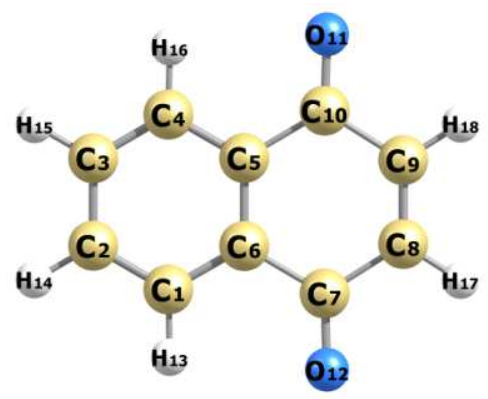

(d)

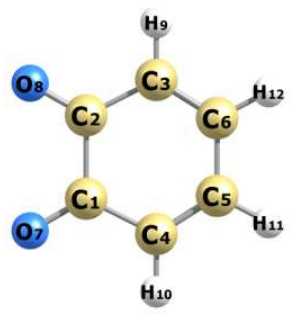

(b)

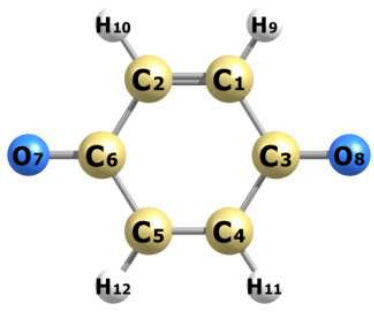

(c)

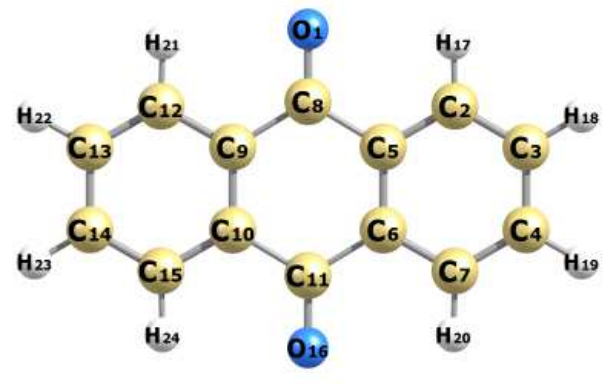

(e)

Figure 1. Optimized geometrical structures of the species: (a) phenol; (b) 1,2-benzoquinone; (c) 1,4-benzoquinone; (d) 1,4- naphtoquinone; (e) 9,10-antraquinone.

Bond angles inside and outside benzene ring are all equal to $120.0^{\circ}$, only one angle $\mathrm{C} 2-\mathrm{O} 1-\mathrm{H} 8$ differs from others and equal to $109.5^{\circ}$. The microwave experimental geometrical parameters reported in [23] are O1-C2 1.374 $\AA, \mathrm{O} 1-\mathrm{H} 80.957$
$\AA$, the C-H 1.081-1.086 $\AA$ and C-C 1.391-1.395 $\AA$, the bond angle is $\mathrm{C}-\mathrm{O}-\mathrm{H} 108.8^{\circ}$. The calculated geometrical parameters are in agreement with experimental data.

1,2-BQ and 1,4-BQ. The molecular structures of 1,2-BQ 
and 1,4-BQ differ only in the position of the oxygen group attached to a benzene ring (Figs. 1b, 1c). The results on the selected geometrical parameters are presented in Table 2 .

The selected calculated bond lengths and bond angles of 1,2-BQ are $\mathrm{C} 1-\mathrm{C} 2, \mathrm{C} 2-\mathrm{C} 3, \mathrm{C} 3=\mathrm{C} 6, \mathrm{C} 1=\mathrm{O} 7$ and $\mathrm{C} 2=\mathrm{O} 8$ which are equal to $1.568,1.473,1.345,1.210$, and $1.210 \AA$. The optimize angles are $\mathrm{C} 2-\mathrm{C} 1-\mathrm{O} 7$ equal to $120.6^{\circ}$ and $\mathrm{C}-\mathrm{C}-\mathrm{C}$ ranged from $\sim 119-121^{\circ}$. The computed selected structural parameters are comparable to experimental results obtained from single-crystal X-ray diffraction [11, 24]. The bond lengths are equal to $1.541,1.463,1.366,1.216$ and $1.216 \AA$, respectively; the valence angles are in the range $117-122^{\circ}[11$, 24]. It is distinctly found out that our geometrical parameters calculated are in the closest agreement with experimental results. The geometrical parameters of this molecule has been also computed in [11] using different methods of DFT including BLYP/6-31G(d) and B3LYP/6-31G(d), the calculated results are in good agreement with our data.

The selected computed geometrical parameters of the 1,4-BQ molecule are equal to $1.339(\mathrm{C} 1=\mathrm{C} 2), 1.486(\mathrm{C} 1-\mathrm{C} 3)$, $1.220(\mathrm{C}=\mathrm{O}), 1.085 \AA(\mathrm{C} 5-\mathrm{H} 12)$ and $117.2^{\circ}(\mathrm{C} 2-\mathrm{C} 6-\mathrm{C} 5)$. The accompanying data in Table 2 are some selected experimental geometrical parameters determined by electron diffraction in gaseous phase [25]: $1.344(\mathrm{C} 1=\mathrm{C} 2), 1.481$ (C1-C3), is, $1.225(\mathrm{C}=\mathrm{O}), 1.089 \AA(\mathrm{C}-\mathrm{H})$ and $118.1^{\circ}$ (C2-C6-C5). It is seen that there is no big difference between computed and experimental results reported in [25].
Table 1. Geometrical parameters of phenol.

\begin{tabular}{lll}
\hline Parameter & B3LYP5/6-311++G(d,p) & Expt [23] \\
\hline Bond lengths, $\AA$ & & \\
O1-C2 & 1.371 & 1.374 \\
C2-C3 & 1.395 & 1.391 \\
C2-C5 & 1.395 & 1.391 \\
C3-C4 & 1.390 & 1.392 \\
C4-C7 & 1.395 & 1.395 \\
C5-C6 & 1.393 & 1.394 \\
C6-C7 & 1.392 & 1.395 \\
O1-H8 & 0.963 & 0.957 \\
C3-H9 & 1.084 & 1.081 \\
C4-H10 & 1.085 & 1.083 \\
C5-H11 & 1.082 & 1.086 \\
C6-H12 & 1.085 & 1.083 \\
Bond angles, deg & & \\
C3-C4-C7 & 120.0 & 120.7 \\
C3-C2-O1 & 117.3 & 117.0 \\
C5-C2-O1 & 122.5 & 122.1 \\
C2-C5-H11 & 120.0 & 120.0 \\
C2-O1-H8 & 109.6 & 108.8 \\
\hline
\end{tabular}

Our data for 1,4-BQ are also in agreement with the theoretical results calculated earlier [26]. It may be also observed that some bond lengths like $\mathrm{C}=\mathrm{O}$ and $\mathrm{C}-\mathrm{H}$ of two species, 1,2-BQ and 1,4-BQ, are almost the same, respectively.

Table 2. Geometrical parameters of 1,2-benzoquinone and 1,4-benzoquinone.

\begin{tabular}{|c|c|c|c|c|c|}
\hline $\begin{array}{l}\text { 1,2-Benzoquinone } \\
\text { Parameter }\end{array}$ & B3LYP5/6-311++G(d,p) & Expt $[11,24]$ & $\begin{array}{l}\text { 1,4-Benzoquinone } \\
\text { Parameter }\end{array}$ & B3LYP5/6-311++G(d,p) & Expt [25] \\
\hline \multicolumn{6}{|l|}{ Bond lengths, $\AA$} \\
\hline $\mathrm{C} 1-\mathrm{C} 2$ & 1.568 & 1.541 & $\mathrm{C} 1=\mathrm{C} 2$ & 1.339 & 1.344 \\
\hline $\mathrm{C} 2-\mathrm{C} 3$ & 1.473 & 1.463 & $\mathrm{C} 1-\mathrm{C} 3$ & 1.486 & 1.481 \\
\hline $\mathrm{C} 3=\mathrm{C} 6$ & 1.345 & 1.366 & $\mathrm{C} 3-\mathrm{C} 4$ & 1.486 & \\
\hline C5-C6 & 1.462 & 1.445 & $\mathrm{C} 4-\mathrm{C} 5$ & 1.486 & \\
\hline $\mathrm{C} 4=\mathrm{C} 5$ & 1.345 & 1.336 & C5-C6 & 1.486 & 1.481 \\
\hline $\mathrm{C} 1-\mathrm{C} 4$ & 1.473 & 1.463 & $\mathrm{C} 2-\mathrm{C} 6$ & 1.486 & \\
\hline $\mathrm{C} 1=\mathrm{O} 7$ & 1.210 & 1.216 & $\mathrm{C} 3=\mathrm{O} 8$ & 1.220 & 1.225 \\
\hline $\mathrm{C} 2=\mathrm{O} 8$ & 1.210 & 1.216 & $\mathrm{C} 6=\mathrm{O} 7$ & 1.220 & 1.225 \\
\hline C3-H9 & 1.084 & & C4-H11 & 1.085 & \\
\hline C4-H10 & 1.085 & & $\mathrm{C} 5-\mathrm{H} 12$ & 1.085 & 1.089 \\
\hline \multicolumn{6}{|l|}{ Bond angles, deg } \\
\hline $\mathrm{C} 2-\mathrm{C} 1-\mathrm{O} 7$ & 120.6 & 119.9 & $\mathrm{C} 1-\mathrm{C} 3-\mathrm{O} 8$ & 121.4 & \\
\hline $\mathrm{C} 2-\mathrm{C} 1-\mathrm{C} 4$ & 118.6 & 117.2 & $\mathrm{C} 2-\mathrm{C} 6-\mathrm{C} 5$ & 117.2 & \\
\hline $\mathrm{C} 1-\mathrm{C} 4-\mathrm{C} 5$ & 120.0 & 120.5 & $\mathrm{C} 2-\mathrm{C} 6-\mathrm{O} 7$ & 121.4 & \\
\hline C6-C5-C4 & 121.3 & 122.3 & $\mathrm{C} 1-\mathrm{C} 2-\mathrm{H} 10$ & 122.7 & \\
\hline C4-C5-H11 & 120.0 & & $\mathrm{C} 2-\mathrm{C} 6-\mathrm{C} 5$ & 117.3 & 118.1 \\
\hline
\end{tabular}

Table 3. Selected geometrical parameters of 1,4-naphthoquinone and 9,10-antraquinone.

\begin{tabular}{|c|c|c|c|c|c|c|}
\hline $\begin{array}{l}\text { 1,4-naphthoquinone } \\
\text { Parameter }\end{array}$ & B3LYP5/ 6-311++G(d,p) & Expt [27] & $\begin{array}{l}\text { 9,10-antraquinone } \\
\text { Parameter }\end{array}$ & B3LYP5/ 6-311++G(d,p) & Expt [28] & Expt [29] \\
\hline \multicolumn{7}{|l|}{ Bond lengths, $\AA$} \\
\hline $\mathrm{C} 1-\mathrm{C} 2$ & 1.394 & 1.43 & $\mathrm{O} 1=\mathrm{C} 8$ & 1.229 & 1.220 & 1.220 \\
\hline C1-C6 & 1.398 & 1.36 & $\mathrm{C} 2-\mathrm{C} 5$ & 1.399 & 1.383 & 1.400 \\
\hline $\mathrm{C} 2-\mathrm{C} 3$ & 1.400 & 1.41 & $\mathrm{C} 2-\mathrm{C} 3$ & 1.392 & 1.390 & 1.400 \\
\hline $\mathrm{C} 4-\mathrm{C} 5$ & 1.398 & 1.39 & $\mathrm{C} 3-\mathrm{C} 4$ & 1.399 & 1.381 & 1.400 \\
\hline $\mathrm{C} 5-\mathrm{C} 6$ & 1.409 & 1.39 & $\mathrm{C} 6-\mathrm{C} 7$ & 1.400 & 1.380 & 1.400 \\
\hline C6-C7 & 1.492 & 1.48 & C6-C11 & 1.491 & 1.495 & \\
\hline $\mathrm{C} 1-\mathrm{H} 13$ & 1.086 & & $\mathrm{C} 8-\mathrm{C} 9$ & 1.491 & 1.495 & 1.499 \\
\hline C3-H15 & 1.087 & & C9-C12 & 1.399 & 1.380 & \\
\hline $\mathrm{C} 5-\mathrm{C} 10$ & 1.492 & 1.43 & $\mathrm{C} 10-\mathrm{C} 11$ & 1.491 & 1.472 & \\
\hline
\end{tabular}




\begin{tabular}{|c|c|c|c|c|c|c|}
\hline $\begin{array}{l}\text { 1,4-naphthoquinone } \\
\text { Parameter }\end{array}$ & B3LYP5/ 6-311++G(d,p) & Expt [27] & $\begin{array}{l}\text { 9,10-antraquinone } \\
\text { Parameter }\end{array}$ & B3LYP5/ 6-311++G(d,p) & Expt [28] & Expt [29] \\
\hline $\mathrm{C} 7-\mathrm{C} 8$ & 1.485 & 1.45 & $\mathrm{C} 12-\mathrm{C} 13$ & 1.392 & 1.380 & \\
\hline $\mathrm{C} 8=\mathrm{C} 9$ & 1.344 & 1.31 & $\mathrm{C} 13-\mathrm{C} 14$ & 1.399 & 1.388 & \\
\hline $\mathrm{C} 7=\mathrm{O} 12$ & 1.225 & 1.22 & $\mathrm{C} 14-\mathrm{C} 15$ & 1.392 & 1.388 & \\
\hline $\mathrm{C} 10=\mathrm{O} 11$ & 1.225 & 1.21 & C2-H17 & 1.085 & 1.080 & 1.087 \\
\hline $\mathrm{C} 8-\mathrm{H} 17$ & 1.087 & & C3-H18 & 1.086 & 1.080 & 1.087 \\
\hline C9-H18 & 1.087 & & & & & \\
\hline \multicolumn{7}{|l|}{ Bond angles, deg } \\
\hline C2-C1-C6 & 121.3 & 121.5 & $\mathrm{C} 2-\mathrm{C} 5-\mathrm{C} 6$ & 120.2 & & 120.1 \\
\hline C6-C7-O12 & 118.9 & 118.0 & $\mathrm{C} 2-\mathrm{C} 3-\mathrm{C} 4$ & 120.0 & & \\
\hline C6-C7-C8 & 120.1 & & $\mathrm{C} 3-\mathrm{C} 2-\mathrm{C} 5$ & 119.7 & & 117.4 \\
\hline C7-C8-C9 & 119.7 & & $\mathrm{C} 2-\mathrm{C} 5-\mathrm{C} 6$ & 120.2 & & \\
\hline
\end{tabular}

1,4-NQ. The 1,4-NQ molecule comprises of two parts one is enedione structure and benzenoid structure (Fig. 1d). The geometrical parameters are presented in Table 3. The calculated aromatic bond lengths C-C are (1.340-1.460) $\AA$, the single bond lengths $\mathrm{C}-\mathrm{C}$ are (1.355-1.462) $\AA$, the double $\mathrm{C} 8=\mathrm{C} 9$ is $1.344 \AA$, the two $\mathrm{C}=\mathrm{O}$ are equal to $1.225 \AA$ and $\mathrm{C}$-H are all equal to $1.087 \AA$. The crystal phase $\mathrm{X}$-ray diffraction data [27] are given in Table 3 for comparison. The experimental values $\mathrm{C} 1-\mathrm{C} 2, \mathrm{C} 1-\mathrm{C} 6, \mathrm{C} 10=\mathrm{O} 11$ and $\mathrm{C} 7=\mathrm{O} 12$ of the 1,4-NQ are found to be $1.43 \AA, 1.36 \AA, 1.21 \AA$ and $1.22 \AA$, respectively [27]. Our computed results in general do not contradict with the experimental results. But for $\mathrm{C} 1-\mathrm{C} 2$, $\mathrm{C} 5-\mathrm{C} 10, \mathrm{C} 7-\mathrm{C} 8$ the deviation is rather big approaching 0.04-0.06 $\AA$. The optimized geometrical parameters of $1,4-\mathrm{NQ}$ molecule have been also found theoretically in [13]; our data are in agreement with these results.

9,10-AQ. The calculated parameters listed in Table 3 show that the carbon-carbon bond lengths are ranged between $1.392-1.491 \AA$, the $\mathrm{C}=\mathrm{O}$ is $1.229 \AA$ and the $\mathrm{C}-\mathrm{H}$ is 1.085-1.086 $\AA$. The bond angles $\mathrm{C}-\mathrm{C}-\mathrm{C}$ are in the range $119.7-120.2^{\circ}, \mathrm{C}-\mathrm{C}-\mathrm{H}$ is $120.0^{\circ}$. Earlier the theoretical geometrical parameters of 9,10-AQ have been obtained using semiempirical methods like ZINDO/1 and AM1 [14]. The experimental data have been also reported for anthraquinone: X-ray data for crystal [28] and electron diffraction for gas phase [29]. The experimental results are as follows: 1.380-1.400 $\AA$ (C-C aromatic bonds), 1.472-1.499 $\AA$ (C-C, single bonds), $1.220 \AA(\mathrm{C}=\mathrm{O})$, and 1.080-1.087 $\AA$ (C-H). Our results are in a very good agreement with data of electron diffraction gas phase [29] and do not contradict to the X-ray data for crystal structure [28]. The maximum deviation of $0.018 \AA$ between our parameters and X-ray values is observed for C2-C5 and C4-C3 bonds.

\subsection{Vibrational Spectra Analysis}

The vibrational spectra of molecules under investigation were determined theoretically for optimized geometrical structures. The analysis of computed vibrational spectra was made relative to the most significant group of frequencies for the most common functional groups and structural components found in organic compounds.

Phenol, 1,2-BQ and 1,4-B. Theoretical spectra of phenol (Fig. 2 a), shows two different regions of vibrations. It is seen that intensive vibrations are found in the first low frequency region of spectra start from $300 \mathrm{~cm}^{-1}$ to $1650 \mathrm{~cm}^{-1}$, that correspond to $\mathrm{H}-\mathrm{O}$ bend vibrations with peak at $305 \mathrm{~cm}^{-1}$, $\mathrm{C}-\mathrm{H}$ wagging with peaks at $763 \mathrm{~cm}^{-1}, \mathrm{C}-\mathrm{H}$ rocking and bending vibrations with peak at $1194 \mathrm{~cm}^{-1}, \mathrm{C}-\mathrm{C}-\mathrm{O}$ stretching and $\mathrm{C}-\mathrm{H}$ bend vibrations with peak at $1273 \mathrm{~cm}^{-1}$, and $\mathrm{C}-\mathrm{C}$ stretching vibrations with peak at $1638 \mathrm{~cm}^{-1}$. The $\mathrm{C}-\mathrm{H}$ and $\mathrm{H}-\mathrm{O}$ stretching vibrations are found in the second region with peaks at $3162 \mathrm{~cm}^{-1}$ and $3864 \mathrm{~cm}^{-1}$ respectively. The experimental vibrational frequencies of phenol measured in vapour by Evans [30] and Green [31] are located in the range of $\left(300-3800 \mathrm{~cm}^{-1}\right)$ and $\left(408-3623 \mathrm{~cm}^{-1}\right)$ respectively. The IR spectra measured in vacuum and reported by NIST (National Institute of standards and Technology) [32] are found in the range of $\left(400-4000 \mathrm{~cm}^{-1}\right)$ as shown in Fig.2b. It is distinctly seen that our computed IR spectra are in good accordance with the experimental spectra.

The theoretical IR spectra of 1,2-BQ is shown in Fig. 3.

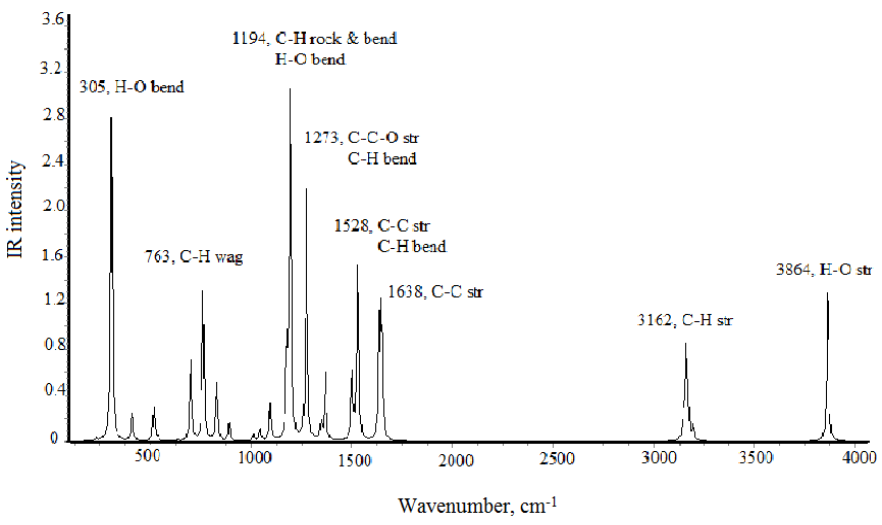

(a)

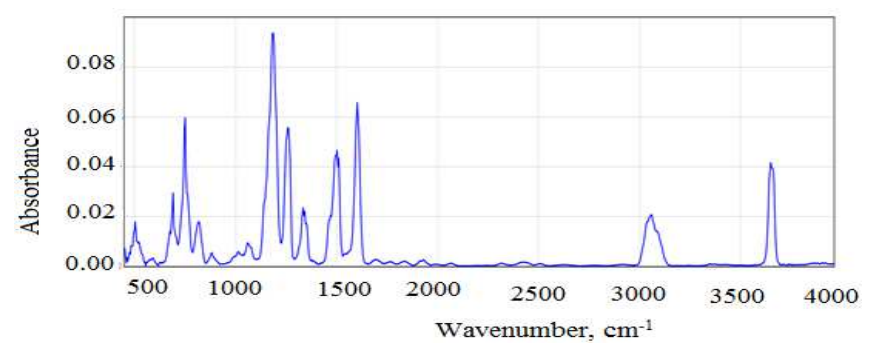

(b)

Figure 2. The IR spectrum of phenol: (a) theoretical spectrum for vacuum computed by B3LYP5/6-311++G(d,p); here and hereafter in Figs. 3, 4a, 5a, and $6 a$, the unit of IR intensity is $D^{2} /\left(a m u \cdot A^{2}\right)$, (b) experimental spectrum measured in gas phase [32]. 


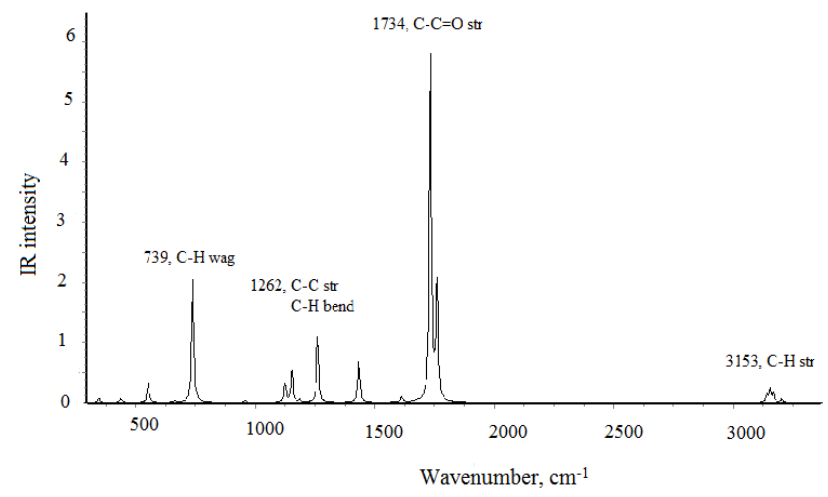

Figure 3. Theoretical IR spectrum of 1,2-benzoquinone computed for vacuum by $B 3 L Y P / 6-311++G(d, p)$.

As may be observed, the most intensive vibrations correspond to the $\mathrm{C}-\mathrm{H}$ wagging, $\mathrm{C}-\mathrm{C}$ stretching, $\mathrm{C}-\mathrm{H}$ bending and $\mathrm{C}=\mathrm{O}$ stretching vibrations with peak at 739, 1262, 1734 and $3153 \mathrm{~cm}^{-1}$. The less intensive and broad vibrations are found in the second region of spectra at high frequencies which relate to $\mathrm{C}-\mathrm{H}$ stretching vibrations. From the best of our knowledge, there is no experimental IR spectra of 1,2-benzoquinone up to now.

The theoretical infrared spectra of 1,4-benzoquinone (Fig. 4a) has a most intensive peak at $1723 \mathrm{~cm}^{-1}$ which relates to the stretching mode of the $\mathrm{C}-\mathrm{C}=\mathrm{O}$ fragment. The $\mathrm{C}-\mathrm{H}$ stretching modes of very low intensity are found in the second region ranged from 3190 to $3230 \mathrm{~cm}^{-1}$. In the experimental spectra measured in gas phase [32] the characteristic peak of high intensity is seen at $1700 \mathrm{~cm}^{-1}$ (Fig $4 \mathrm{~b})$. The vibrational bands data reported in [33] are ranged from 105 up to $3062 \mathrm{~cm}^{-1}$, so there is a good correlation to our computed results.

1,4-NQ and 9,10-AQ. Theoretical spectra of the species are shown in Figs. 5a and 6a. Similarly to other quinone derivatives, 1.2-BQ and 1,4-BQ, the spectra of 1,4-NQ the most intensive vibration frequencies correspond to $\mathrm{C}-\mathrm{H}$ wagging, $\mathrm{C}-\mathrm{H}$ bending, $\mathrm{C}-\mathrm{C}=\mathrm{O}$ stretching vibrations with peaks at 759,1340 and $1710 \mathrm{~cm}^{-1}$ respectively. The bands of very low intensities relate to the $\mathrm{C}-\mathrm{H}$ stretching modes. Experimental data measured in gas phase [32] show the characteristic peak at $1700 \mathrm{~cm}^{-1}$ (Fig. 5b), that is the theoretical value $1710 \mathrm{~cm}^{-1}$ is in agreement with the experimental one. For other bands, the agreement between our theoretical spectrum and experimental one [32] also is observed. Worth to mention that our results are in accordance with the theoretical vibrational spectrum of 1,4-NQ calculated in [13], in which the maximum peak is located at $1729 \mathrm{~cm}^{-1}$ and the most intensive vibration bands are observed in region from $\sim 700$ to $1800 \mathrm{~cm}^{-1}$.

In the theoretical IR spectrum of 9,10-antraquinone (Fig. $6 \mathrm{a})$, the most intensive bands are found in the region from $\sim 400$ up to $\sim 1810 \mathrm{~cm}^{-1}$; the intensive vibrations correspond to $\mathrm{C}-\mathrm{H}$ wagging, $\mathrm{C}-\mathrm{H}$ bending, $\mathrm{C}-\mathrm{C}$ stretching, $\mathrm{C}-\mathrm{C}=\mathrm{O}$ stretching vibrations with peaks at 690, 1353, 1545, and 1806 $\mathrm{cm}^{-1}$ respectively.

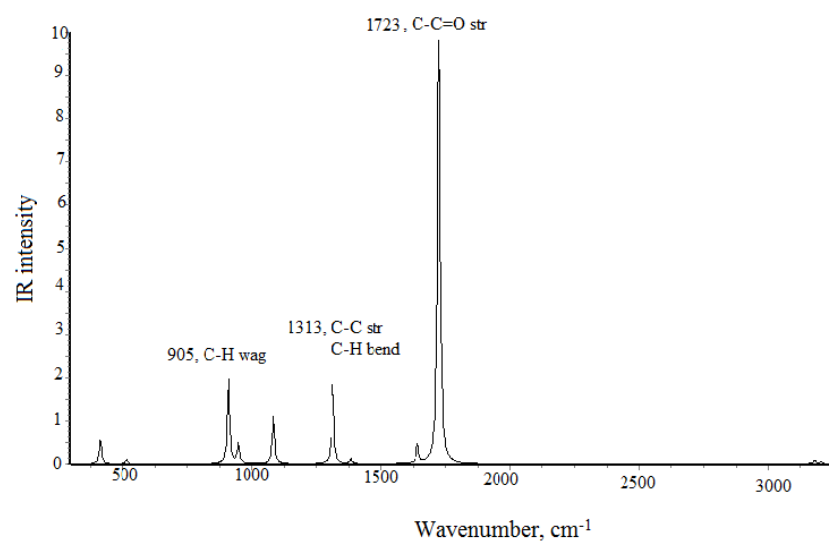

(a)

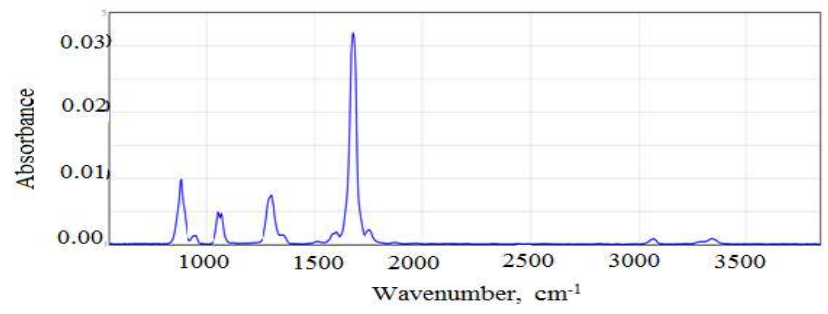

(b)

Figure 4. The IR spectrum of 1,4-benzoquinone: (a) theoretical spectrum for vacuum computed by B3LYP5/6-311++G(d,p); (b) experimental spectrum of measured in gas phase [32].

The bands of low intensities are observed at $\sim 3800 \mathrm{~cm}^{-1}$, which correspond to $\mathrm{C}-\mathrm{H}$ stretching vibrations. The first two intensive peaks (690 and $1353 \mathrm{~cm}^{-1}$ ) seen in our spectrum correspond to experimental ones, $\sim 740$ and $\sim 1300 \mathrm{~cm}^{-1}$ [32]. Nevertheless the position and relative intensities of other peaks in our spectrum for the range $1500-2000 \mathrm{~cm}^{-1}$, differ from those in experimental one. But the last two intensive peaks $\left(\sim 1700\right.$ and $\left.1800 \mathrm{~cm}^{-1}\right)$, being considered as merged together, may fit the most intensive peak of $\sim 1700 \mathrm{~cm}^{-1}$ in the experimental spectrum.

Based on the calculated vibrational frequencies and optimized geometrical parameters of the species the thermodynamic functions of species have been calculated; the results are given in Appendix.

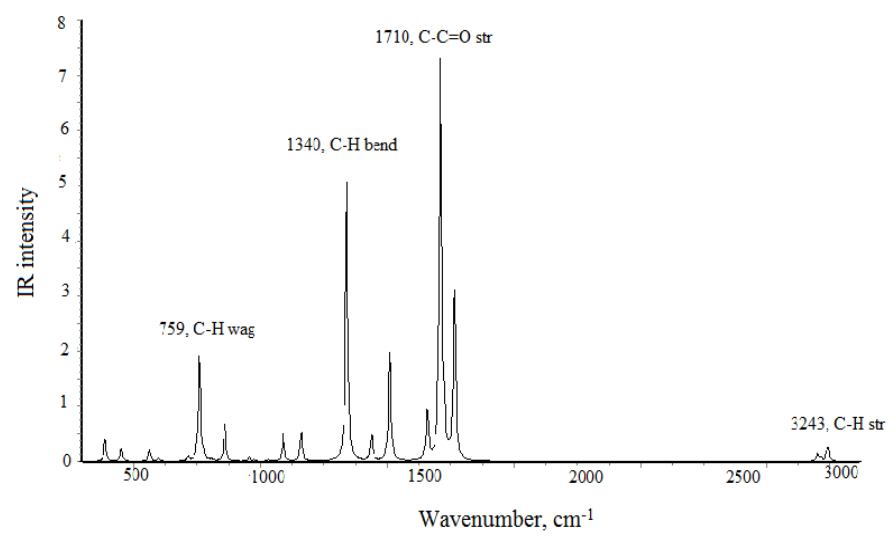

(a) 


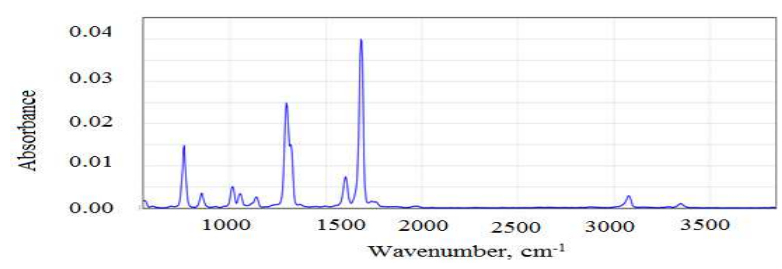

(b)

Figure 5. The IR spectrum of 1,4-naphthoquinone: (a) theoretical spectrum computed for vacuum by B3LYP5/6-311++G(d,p), (b) experimental spectrum of measured in gas phase [32].

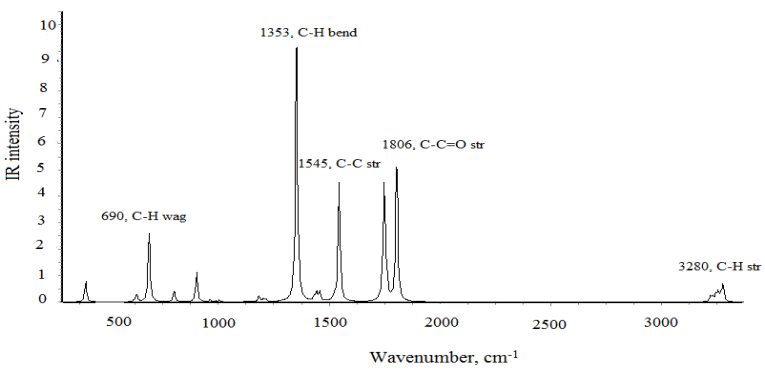

(a)

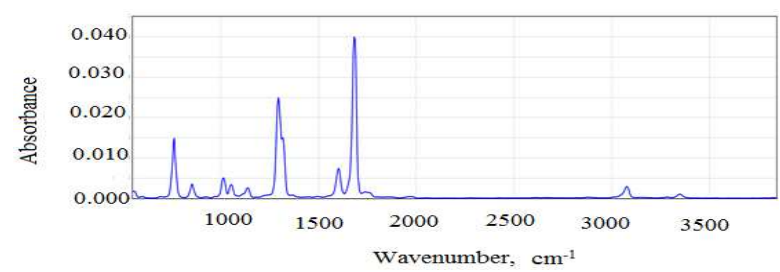

(b)

Figure 6. (a) Theoretical IR spectrum of 9,10-antraquinone computed for vacuum by $B 3 L Y P / 6-311++G(d, p)$; (b) experimental IR spectra of 9,10-antraquinone measured in gas phase [32].

\subsection{Electronic Absorption Spectra Analysis}

Electronic absorption spectra of molecules under study were computed for vacuum and solutions using the polarized continuum model. The computed energy of excitation $\left(E_{e x}\right)$, absorption wavelength $(\lambda)$, oscillator strength (f), electronic transition configurations and experimental reported wavelength ( $\lambda \exp )$ are summarized in Table 4 . Only singletsinglet $(\mathrm{S} 0 \rightarrow \mathrm{Sex})$ transitions have been considered, no $\mathrm{S} \rightarrow \mathrm{T}$ excitations taken into account. The choice of solvents, water for phenol and 1,2-BQ and heptane for 1,4-BQ, 1,4-NQ and $9,10-A Q$, related to the available experimental data [15, 34].

Phenol. The computed absorption spectrum of phenol in vacuum (Fig. 7a) shows that phenol has three bands of moderate oscillator strength at 240, 208 and $179 \mathrm{~nm}$. As may be observed in Table 4 excitation energy, oscillator strength and electronic transition configurations at a maximum absorption wavelength $(240 \mathrm{~nm})$ are almost the same in vacuum and water solution. When compared the computed and reference data, an agreement is observed for the band at $208 \mathrm{~nm}$ (vacuum) and $207 \mathrm{~nm}$ (water solution) with $205 \mathrm{~nm}$ (gas), and $210 \mathrm{~nm}$ (water solution) from [32, 34]. Nevertheless, mismatch is seen for the theoretical peak at 240 $\mathrm{nm}$, as no band occurs in the experimental spectrum at this wavelength. At the same time, a broadened band is observed between $\sim 260$ and $280 \mathrm{~nm}$ (Fig. 7b).

As for DSSC application, phenol cannot be appropriate component as the absorption bands are located in ultraviolet $\mathrm{C}$ range (280-100 nm). In this part of electromagnetic radiations all light is completely absorbed by the ozone layer in atmosphere.

Table 4. Electronic absorption spectra computed using TDDFT, B3LYP/6-311++G(d,p).

\begin{tabular}{|c|c|c|c|c|c|c|c|c|c|c|}
\hline \multirow{2}{*}{$\begin{array}{l}\text { Vacuum } \\
\text { Molecule }\end{array}$} & \multirow[b]{2}{*}{$\begin{array}{l}\text { Excited } \\
\text { state No. }\end{array}$} & \multirow[b]{2}{*}{$E_{\mathrm{ex}}, \mathrm{eV}$} & \multirow[b]{2}{*}{$\lambda, \mathbf{n m}$} & \multirow[b]{2}{*}{$f$} & \multicolumn{4}{|c|}{ Solution } & \multirow[b]{2}{*}{$\begin{array}{l}\text { Electronic } \\
\text { transition } \\
\text { configurations }\end{array}$} & \multirow[b]{2}{*}{$\lambda_{\exp }{ }^{a}, \mathbf{n m}$} \\
\hline & & & & & $\begin{array}{l}\text { Electronic } \\
\text { transition } \\
\text { configurations }\end{array}$ & $E_{\mathrm{ex}}, \mathrm{eV}$ & $\lambda, \mathbf{n m}$ & $f$ & & \\
\hline \multirow{4}{*}{ Phenol } & 1 & 5.16 & 240 & 0.029 & $\mathrm{H} \rightarrow \mathrm{L}(78 \%)$ & 5.16 & 240 & 0.027 & $\mathrm{H} \rightarrow \mathrm{L}(78 \%)$ & \multirow{6}{*}{$210[34]$} \\
\hline & 3 & 5.76 & 215 & 0.002 & $\mathrm{H} \rightarrow \mathrm{L}+3(99 \%)$ & 5.95 & 208 & 0.041 & $\mathrm{H} \rightarrow \mathrm{L}+1(69 \%)$ & \\
\hline & 4 & 5.96 & 208 & 0.040 & $\mathrm{H} \rightarrow \mathrm{L}+2(69 \%)$ & 5.99 & 207 & 0.002 & $\mathrm{H} \rightarrow \mathrm{L}+3(99 \%)$ & \\
\hline & 5 & 6.06 & 204 & 0.001 & $\mathrm{H}-1 \rightarrow \mathrm{L}+1(96 \%)$ & 6.76 & 184 & 0.002 & $\mathrm{H}-1 \rightarrow \mathrm{L}+3(97 \%)$ & \\
\hline \multirow{2}{*}{ 1,2-BQ } & 5 & 5.45 & 228 & 0.053 & $\mathrm{H}-3 \rightarrow \mathrm{L}(78 \%)$ & 5.16 & 240 & 0.066 & $\mathrm{H}-3 \rightarrow \mathrm{L}(81 \%)$ & \\
\hline & 8 & 6.16 & 201 & 0.003 & $\mathrm{H} \rightarrow \mathrm{L}+3(99 \%)$ & 6.40 & 194 & 0.171 & $\mathrm{H} \rightarrow \mathrm{L}+1(55 \%)$ & \\
\hline & 9 & 6.31 & 196 & 0.111 & $\mathrm{H} \rightarrow \mathrm{L}+3(99 \%)$ & & & & & \multirow{3}{*}{$277[15]$} \\
\hline 1,4-BQ & 4 & 4.94 & 251 & 0.328 & $\mathrm{H}-3 \rightarrow \mathrm{L}(91 \%)$ & 4.85 & 256 & 0.327 & $\mathrm{H}-3 \rightarrow \mathrm{L}(91 \%)$ & \\
\hline \multirow[t]{6}{*}{ 1,4-NQ } & 3 & 3.57 & 348 & 0.011 & $\mathrm{H}-2 \rightarrow \mathrm{L}(94 \%)$ & 3.49 & 355 & 0.010 & $\mathrm{H}-2 \rightarrow \mathrm{L}(95 \%)$ & \\
\hline & 4 & 3.60 & 344 & 0.052 & $\mathrm{H}-1 \rightarrow \mathrm{L}(97 \%)$ & 3.55 & 349 & 0.053 & $\mathrm{H}-1 \rightarrow \mathrm{L}(97 \%)$ & $328[15]$ \\
\hline & 5 & 4.89 & 254 & 0.233 & $\mathrm{H}-4 \rightarrow \mathrm{L}(86 \%)$ & 4.86 & 255 & 0.231 & $\mathrm{H}+4 \rightarrow \mathrm{L}(87 \%)$ & $246[15]$ \\
\hline & 10 & 5.69 & 218 & 0.003 & $H-1 \rightarrow L+1(84 \%)$ & & & & & \\
\hline & 4 & 3.80 & 326 & 0.109 & $\mathrm{H}-3 \rightarrow \mathrm{L}(94 \%)$ & 3.77 & 329 & 0.110 & $\mathrm{H}-3 \rightarrow \mathrm{L}(91 \%)$ & $332[15]$ \\
\hline & 7 & 4.46 & 278 & 0.174 & $\mathrm{H}-5 \rightarrow \mathrm{L}(94 \%)$ & 3.79 & 327 & 0.002 & $\mathrm{H}-1 \rightarrow \mathrm{L}(92 \%)$ & \\
\hline \multirow[t]{3}{*}{ 9,10-AQ } & 9 & 5.00 & 248 & 0.009 & $H-1 \rightarrow L+1(96 \%)$ & 4.44 & 279 & 0.171 & $\mathrm{H}-5 \rightarrow \mathrm{L}(94 \%)$ & 269 [15] \\
\hline & 10 & 5.03 & 247 & 0.467 & $\mathrm{H}-2 \rightarrow \mathrm{L}+1(81 \%)$ & 5.00 & 248 & 0.008 & $H-1 \rightarrow L+1(96 \%)$ & \\
\hline & & & & & & 5.02 & 247 & 0.491 & $\mathrm{H}-2 \rightarrow \mathrm{L}+1(82 \%)$ & 249 [15] \\
\hline
\end{tabular}

Note: ${ }^{a}$ The solvents used were water for phenol and heptane for 1,4-BQ, 1,4-NQ and 9,10-AQ.

1,2-BQ. As shown in Fig. 8, this molecule has three bands of moderate oscillator strength at 396, 228 and $196 \mathrm{~nm}$. The 
experimental spectrum reported in [35] shows also a peak at $\sim 394 \mathrm{~nm}$. When computed in solution (water), the electron transitions were red-shifted to the absorption bands with peaks at 446 and $240 \mathrm{~nm}$. Our results are in good agreement with experimental [35]. Excitation energy at a maximum absorption wavelength was reduced from $3.13 \mathrm{eV}$ in vacuum up to $2.78 \mathrm{eV}$ in water solution.

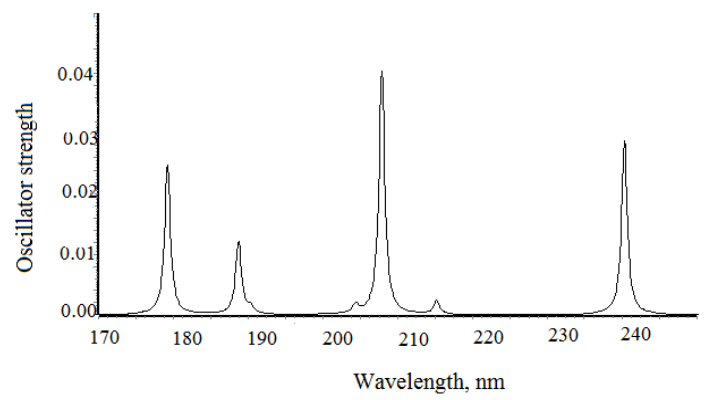

(a)

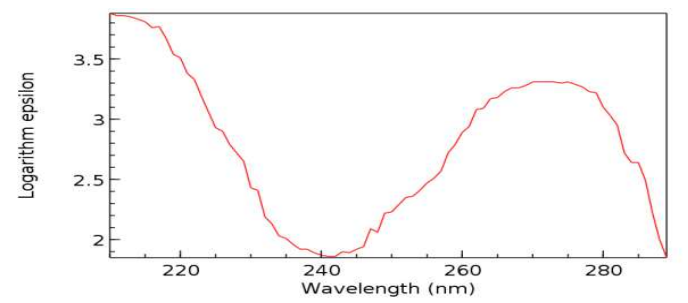

(b)

Figure 7. The UV-Vis absorption spectrum of phenol: (a) theoretical spectrum computed for vacuum using TDDFT, B3LYP/6-311++G(d,p); (b) experimental spectrum [37, 38].

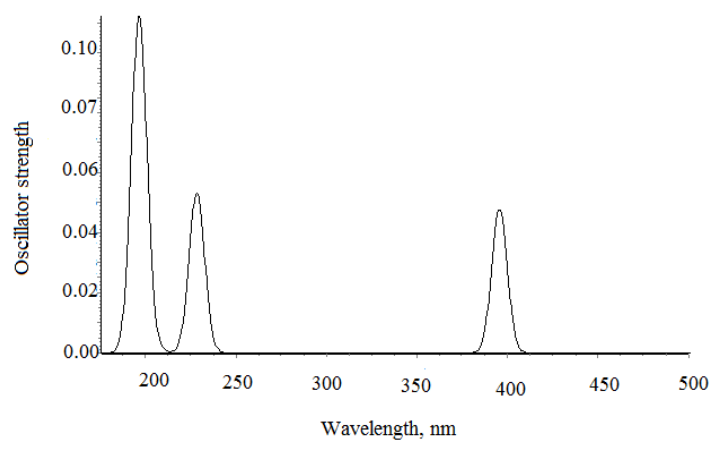

(a)

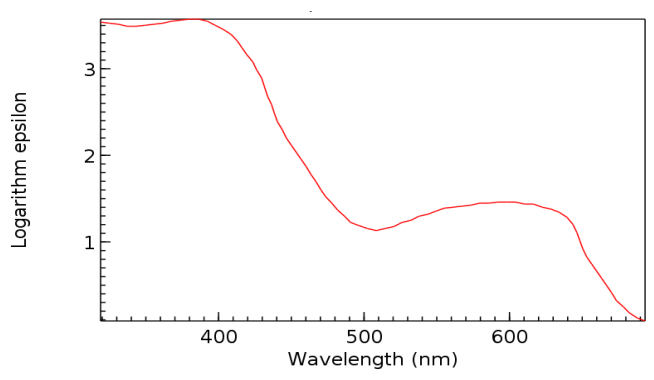

(b)

Figure 8. The UV-Vis absorption spectra of 1,2-benzoquinone: (a) theoretical spectrum computed for vacuum using TDDFT, B3LYP/6-311++G(d,p); (b) experimental spectrum $[35,37]$.

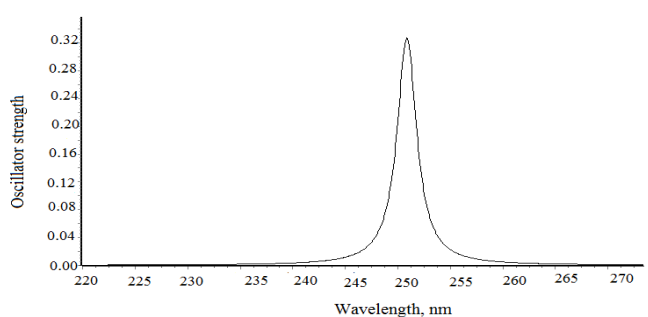

(a)

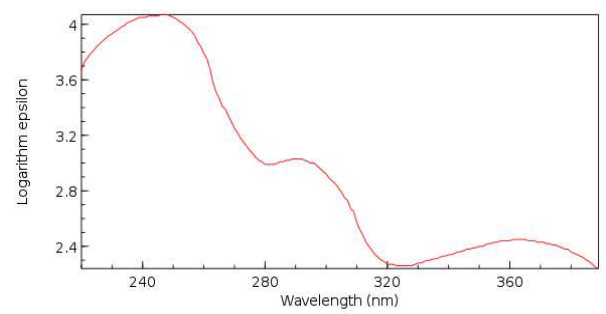

(b)

Figure 9. The UV-Vis absorption spectra of 1,4-benzoquinone: (a) theoretical spectrum computed for vacuum using TDDFT, B3LYP/6-311++G(d,p); (b) experimental spectrum [37].

1,4-BQ. The values of Eex, $\lambda$, and $f$ computed for vacuum are almost the same as the results obtained for heptane solution (Table 4). As may be seen in Fig. 9a, there is the intensive peak at $251 \mathrm{~nm}$ that is in agreement with the most intensive experimental band shown in Fig. 9b. Meanwhile in heptane solution, the agreement is not so good as the maximum experimental wavelength observed is $277 \mathrm{~nm}$ [15] compared to our result of $256 \mathrm{~nm}$.

1,4-NQ. The theoretical UV-Vis spectrum (Fig. 10) computed for vacuum shows four absorption bands at 348, 344, 254 and $231 \mathrm{~nm}$. When computed for heptane solution, the first two bands were red-shifted to 349 and $355 \mathrm{~nm}$ while the position of other two bands has not changed. The experimental data measured in heptane [15] are 328.5, 245.5, and $239.5 \mathrm{~nm}$. A fair correspondence between our computed results and reference data may be noted.

9,10-AQ. The theoretical UV-Vis spectrum for vacuum and experimental one for gas phase are compared on in Figs. 11a and $11 \mathrm{~b}$. A very good accordance is observed. In the computed spectrum for vacuum, the maximum absorption wavelength is $326 \mathrm{~nm}$, while for heptane solution it is red-shifted slightly, by $3 \mathrm{~nm}$. Our computed $\lambda \max$ is in the close agreement with the experimental one measured in heptane solution, $331.8 \mathrm{~nm}$ [15].

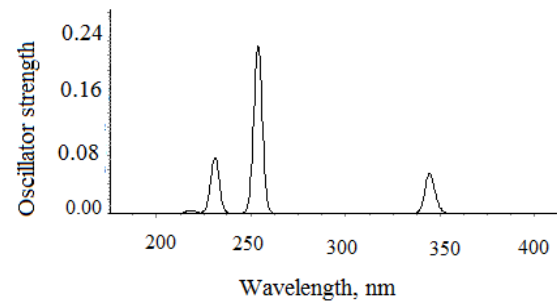

Figure 10. Theoretical UV-Vis absorption spectra of 1,4-naphthoquinone computed for vacuum using TDDFT, B3LYP/6-311++G(d,p). 


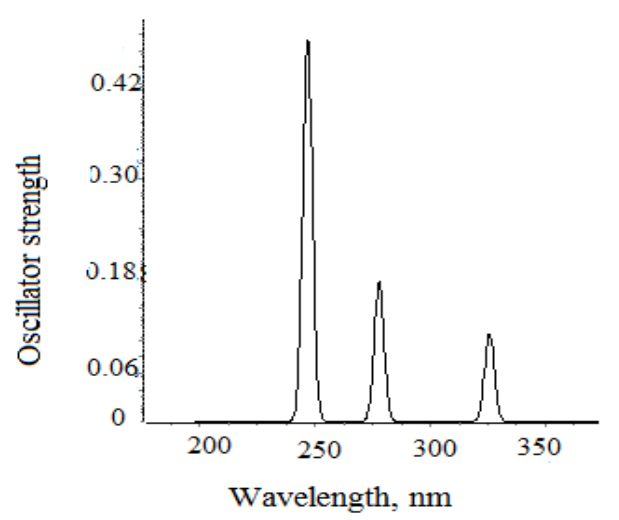

(a)

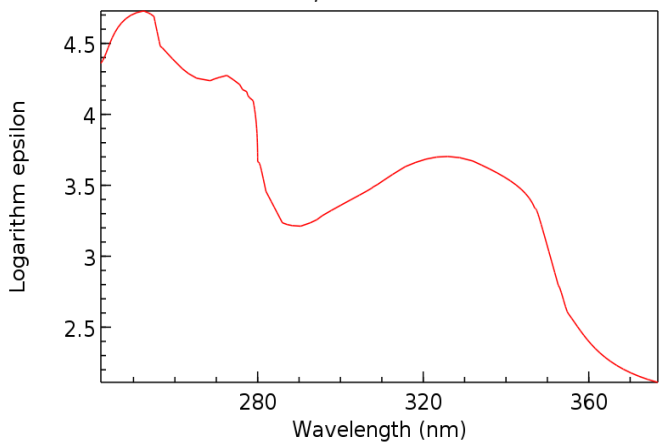

(b)

Figure 11. The UV-Vis absorption spectra of 9,10-antraquinone: (a) theoretical spectrum computed for vacuum using TDDFT, B3LYP/6-311++G(d,p); (b) experimental spectrum [37, 39].

\subsection{Energy Level Alignment}

We performed calculations of highest occupied molecular orbitals (HOMOs), and lowest unoccupied molecular orbitals (LUMOs) of molecules under investigation. Calculations were performed both for vacuum and solutions. The values of HOMOs, LUMOs energies and energy gaps are summarized in Table 5.

Table 5. Molecular orbital energies (in eV) computed at $B 3 L Y P / 6-311++G(d, p)$ level.

\begin{tabular}{lllllll}
\hline Vacuum & & \multicolumn{7}{c}{ Solution } \\
\hline Molecule & HOMO & LUMO & $\boldsymbol{E}_{\mathrm{g}}$ & HOMO & LUMO & $\boldsymbol{E}_{\mathrm{g}}$ \\
\hline Phenol & -6.32 & -0.37 & 5.95 & -6.48 & -0.52 & 5.96 \\
1,2-BQ & -7.17 & -3.96 & 3.21 & -7.49 & -4.08 & 3.41 \\
1,4-BQ & -7.78 & -3.92 & 3.87 & -7.65 & -3.74 & 3.91 \\
1,4-NQ & -7.56 & -3.53 & 4.03 & -7.47 & -3.23 & 4.23 \\
9,10-AQ & -7.37 & -3.18 & 4.19 & -7.63 & -3.56 & 4.07 \\
\hline
\end{tabular}

When proceed from vacuum to solutions, the energies $\varepsilon(\mathrm{HOMO})$ change differently for different species: decrease for phenol, 1,2-BQ, and 9,10-AQ and increase for two other species. As for the energy gap the change is small, the largest being $0.20 \mathrm{eV}$ for 1,2-BQ and 1,4-NQ. Comparing the energy gap $E_{\mathrm{g}}$ with the first excitation energy $E_{\mathrm{ex}}$ (Table 5), the values of $E_{\mathrm{g}}$ are bigger than $E_{\mathrm{ex}}$, and the difference varies between $3 \%$ (1,2-BQ) and 28\% (1,4-BQ).

The energy level alignment between a semiconductor, electrolyte and sensitizer is fundamental for DSSCs. The simplest way to consider this alignment is to apply the energy levels of the frontier orbitals. But the more appropriate way is to use the energy levels calculated by TDDFT [4]. To reveal the ability of a sensitizer to satisfy this alignment, the quantity of the excited state oxidation-potential (ESOP) is used. According to definition, the ESOP is the difference of free energy between neutral and oxidized species in the excited state [5]. In this work the ESOPs were calculated as the sum of ground state $\mathrm{HOMO}$ energy and the singlet-singlet transition excitation energy $E_{\mathrm{ex}}: \mathrm{ESOP}=\varepsilon(\mathrm{HOMO})+E_{\mathrm{ex}}$. To carry out ESOPs calculations, the minimum excitation energy $E_{\mathrm{ex}}$ with non-zero oscillator strength was used.

Figs. $12 \mathrm{a}$ and $12 \mathrm{~b}$ represent the energy levels of the HOMOs and the ESOPs for phenol and quinone derivatives, a nanocrystalline $\mathrm{TiO}_{2}$ electrode $[5]$ and $\mathrm{I}^{-} / \mathrm{I}_{3}{ }^{-}$redox electrolyte $[4,40]$. As it is noted in the introduction, for a dye to be operational and ensuring that there is enough driving force for the dye generation reaction, its HOMO energy level must be located within the band gap of the semiconductor and below electrolyte $\left(\mathrm{I}^{-} / \mathrm{I}_{3}{ }^{-}\right)$redox level, and ESOP to lie a bit above the conduction band of semiconductor $[4,5,36]$.

As may be observed in Fig. 12a, the only HOMO levels of phenol and 1,2-benzoquinone are located within the band gap of $\mathrm{TiO}_{2}$ metal oxide and below the $\mathrm{I}^{-} / \mathrm{I}_{3}{ }^{-}$redox level, this implies that there may be a sufficient driving force for dye generation reaction. The calculated HOMO levels of 1,4-BQ, 1,4-NQ, and 9,10-AQ are found to be out of the band gap of $\mathrm{TiO}_{2}$, this means that these three species do not have enough driving force of the dye generation reaction. The ESOPs computed both for vacuum and solutions of the molecules under study are located above the $\mathrm{TiO}_{2} \mathrm{CB}$ level, except 1,2-benzoquinone shown in Fig. 12b. But the ESOP of phenol is not laid nearby; it is located far above from CB of $\mathrm{TiO}_{2}$. The rest species, 1,4-naphthoquinone, 9,10-antraquinone, 1,2 and 1,4-benzoquinone, may have sufficient driving force for electron injection to $\mathrm{TiO}_{2}$. The calculated absorption wavelengths show that all molecules under study, absorb in the near UV region, the only 1,2-benzoquinone absorb light up to the visible region of the electromagnetic spectrum. From analysis stated above 1,2-benzoquinone molecules show better electronic properties to be a photosensitizer in DSSCs.

\section{Conclusion}

In this work we have studied vibrational and electronic absorption spectra of phenol, 1,2-benzoquinone, 1,4-benzoquinone 1,4-naphthoquinone and 9,10-antraquinone. The calculated theoretical spectra, as well as geometrical parameters, are in an agreement with available experimental data. Based on the ability to absorb light in the visible region, appropriate energy level alignment with the conduction band edge of the semiconductor substrate and the redox level of the electrolyte, 1,2-benzoquinone seems to be a better candidate among the considered molecules for DSSCs. 


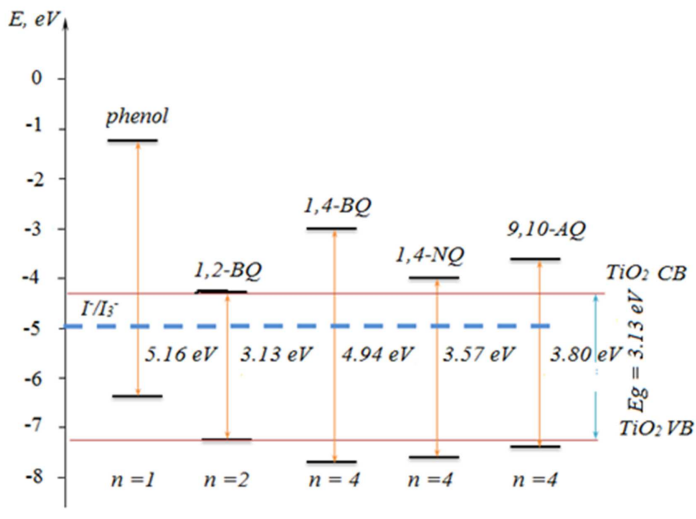

(a)

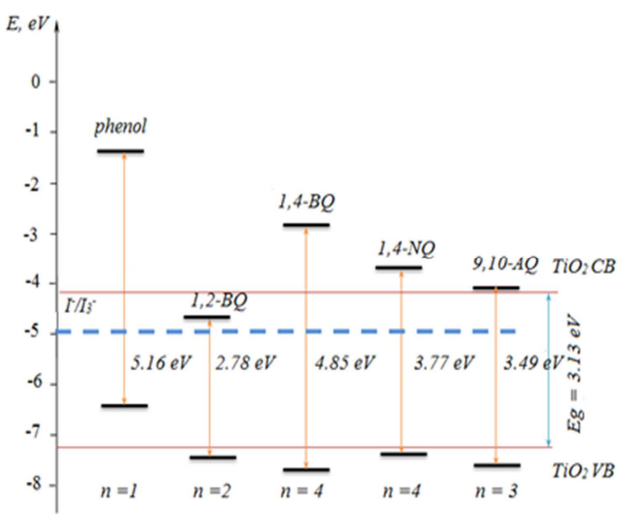

(b)

Figure 12. Schematic energy level representation showing the HOMOs and ESOPs for phenol and quinone derivatives, calculated using TDDFT, B3LYP/ 6-311++G(d,p): (a) vacuum; (b) solutions (water for phenol and 1,2-BQ, heptane for 1,4-BQ, 9,10-AQ and1 1,4-NQ). The valence and conduction bands of a nanocrystalline TiO2 were taken from [4, 5] and redox level of the I-/I3-electrolyte from [5, 40].

\section{Appendix}

The thermodynamic functions of phenol, 1,2-benzoquinone, 1,4-benzoquinone, 1,4-naphthoquinone and 9,10-antraquinone in gaseous phase were calculated using Openthermo software [16]. For temperature interval between $100-1000 \mathrm{~K}$, the molar heat capacity $c_{\mathrm{p}}{ }^{\circ}(T)$; the Gibbs reduced free energy $\Phi^{\circ}$; the entropy $S^{\circ}(T)$; and the enthalpy increment $H^{\circ}(T)-H^{\circ}(0)$ are listed in Table A; the units are $\mathrm{J} \cdot \mathrm{mol}^{-1} \cdot \mathrm{K}^{-1}, \mathrm{~J} \cdot \mathrm{mol}^{-1} \cdot \mathrm{K}^{-1}, \mathrm{~J} \cdot \mathrm{mol}^{-1} \cdot \mathrm{K}^{-1}$ and $\mathrm{kJ} \cdot \mathrm{mol}^{-1}$, respectively. The Gibbs reduced free energy was calculated using the following formula: $\Phi^{\circ}(T)=-\left[\left(H^{\circ}(T)-H^{\circ}(0)\right)-\right.$ $\left.T S^{\circ}(T)\right] / T$. The experimental data for $c_{\mathrm{p}}{ }^{\circ}(T)$ were taken from [41] (phenol), [42] (1,4-BQ), [43] (1,4-NQ and 9-10-AQ). Our computed results for $c_{\mathrm{p}}{ }^{\circ}$ are in good accordance with experimental results; the biggest deviation of $\sim 12 \%$ (at 1000 $\mathrm{K}$ ) is observed for 9,10-antraquinone.

Table A. Thermodynamic functions of phenol, 1,2-benzoquinone, 1,4- benzoquinone, 1,4-naphthoquinone, and 9,10-antraquinone.

\begin{tabular}{|c|c|c|c|c|c|}
\hline \multirow{2}{*}{$T, \mathbf{K}$} & \multicolumn{2}{|l|}{$c_{\mathrm{p}}{ }^{\circ}(T)$} & \multirow[t]{2}{*}{$S^{\circ}(T)$} & \multirow[t]{2}{*}{$H^{\circ}(T)-H^{\circ}(0)$} & \multirow[t]{2}{*}{$\Phi^{\circ}(T)$} \\
\hline & This work & Expt [41-43] & & & \\
\hline \multicolumn{6}{|l|}{ Phenol } \\
\hline 100 & 40.209 & 41.38 & 243.645 & 3.484 & 208.805 \\
\hline 200 & 67.189 & 69.65 & 279.145 & 8.760 & 235.345 \\
\hline 298.15 & 99.576 & 94.61 & 311.955 & 16.931 & 255.168 \\
\hline 300 & 100.190 & 103.86 & 312.573 & 17.116 & 255.519 \\
\hline 400 & 131.600 & 135.79 & 345.796 & 28.740 & 273.946 \\
\hline 500 & 157.950 & 161.91 & 378.095 & 43.263 & 291.569 \\
\hline 600 & 179.100 & 182.48 & 408.833 & 60.155 & 308.574 \\
\hline 700 & 196.100 & 198.84 & 437.764 & 78.944 & 324.986 \\
\hline 800 & 210.010 & 212.14 & 464.887 & 99.272 & 340.797 \\
\hline 900 & 221.590 & 223.19 & 490.310 & 120.869 & 356.011 \\
\hline 1000 & 231.380 & 232.49 & 514.178 & 143.530 & 370.648 \\
\hline \multicolumn{6}{|l|}{$1,2-\mathrm{BQ}$} \\
\hline 100 & 47.359 & & 243.536 & 3.857 & 204.966 \\
\hline 200 & 75.503 & & 284.578 & 9.940 & 234.878 \\
\hline 298.15 & 105.990 & & 327.878 & 18.977 & 264.228 \\
\hline 300 & 106.210 & & 321.029 & 19.033 & 257.585 \\
\hline 400 & 134.070 & & 355.502 & 31.083 & 277.794 \\
\hline 500 & 157.250 & & 387.998 & 45.689 & 296.620 \\
\hline 600 & 175.920 & & 418.381 & 62.382 & 314.411 \\
\hline 700 & 190.960 & & 446.670 & 80.753 & 331.308 \\
\hline 800 & 203.200 & & 472.995 & 100.482 & 347.392 \\
\hline 900 & 213.310 & & 497.531 & 121.323 & 362.727 \\
\hline 1000 & 221.750 & & 520.456 & 143.088 & 377.368 \\
\hline \multicolumn{6}{|l|}{ 1,4-BQ } \\
\hline 100 & 47.359 & 47.65 & 243.536 & 3.857 & 204.966 \\
\hline 200 & 75.503 & 76.51 & 284.578 & 9.940 & 234.878 \\
\hline 298.15 & 105.660 & 107.39 & 320.374 & 18.837 & 257.194 \\
\hline 300 & 106.210 & 107.95 & 321.029 & 19.033 & 257.585 \\
\hline 400 & 134.070 & 136.31 & 355.502 & 31.083 & 277.794 \\
\hline
\end{tabular}




\begin{tabular}{|c|c|c|c|c|c|}
\hline \multirow{2}{*}{$T, \mathbf{K}$} & \multicolumn{2}{|l|}{$c_{\mathrm{p}}{ }^{\circ}(T)$} & \multirow[t]{2}{*}{$S^{\circ}(T)$} & \multirow[t]{2}{*}{$H^{\circ}(T)-H^{\circ}(0)$} & \multirow[t]{2}{*}{$\Phi^{\circ}(T)$} \\
\hline & This work & Expt [41-43] & & & \\
\hline 500 & 157.250 & 159.73 & 387.998 & 45.689 & 296.620 \\
\hline 600 & 175.920 & 178.51 & 418.381 & 62.382 & 314.411 \\
\hline 700 & 190.960 & 193.57 & 446.670 & 80.753 & 331.308 \\
\hline 800 & 203.200 & 205.80 & 472.995 & 100.482 & 347.392 \\
\hline 900 & 213.310 & 215.86 & 497.531 & 121.323 & 362.727 \\
\hline 1000 & 221.750 & 224.22 & 520.456 & 143.088 & 377.368 \\
\hline \multicolumn{6}{|l|}{ 1,4-NQ } \\
\hline 100 & 60.716 & 62.71 & 272.432 & 4.385 & 228.582 \\
\hline 200 & 104.56 & 100.82 & 327.449 & 12.573 & 264.584 \\
\hline 298.15 & 151.980 & 148.53 & 378.033 & 25.163 & 293.635 \\
\hline 300 & 152.86 & 150.22 & 378.976 & 25.445 & 294.159 \\
\hline 400 & 197.66 & 196.51 & 429.236 & 43.023 & 321.678 \\
\hline 500 & 235.17 & 236.28 & 477.517 & 64.729 & 348.059 \\
\hline 600 & 265.3 & 268.51 & 523.16 & 89.809 & 373.478 \\
\hline 700 & 289.42 & 301.08 & 565.936 & 117.590 & 397.950 \\
\hline 800 & 308.93 & 315.22 & 605.901 & 147.541 & 421.474 \\
\hline 900 & 324.93 & 332.26 & 643.241 & 179.260 & 444.063 \\
\hline 1000 & 338.21 & 345.98 & 678.184 & 212.436 & 465.748 \\
\hline \multicolumn{6}{|c|}{ 9,10-AQ } \\
\hline 100 & 74.642 & 77.91 & 289.260 & 5.060 & 238.660 \\
\hline 200 & 133.880 & 134.75 & 358.554 & 15.396 & 281.574 \\
\hline 298.15 & 198.340 & 197.78 & 423.979 & 31.689 & 317.693 \\
\hline 300 & 199.550 & 199.03 & 425.209 & 32.057 & 318.352 \\
\hline 400 & 261.300 & 260.18 & 491.268 & 55.168 & 353.348 \\
\hline 500 & 313.170 & 313.10 & 555.347 & 83.981 & 387.385 \\
\hline 600 & 354.780 & 355.77 & 616.267 & 117.458 & 420.503 \\
\hline 700 & 387.980 & 388.79 & 673.545 & 154.657 & 452.606 \\
\hline 800 & 414.730 & 417.60 & 727.161 & 194.839 & 483.612 \\
\hline 900 & 436.590 & 440.28 & 777.313 & 237.441 & 513.489 \\
\hline 1000 & 454.690 & 516.16 & 824.279 & 282.033 & 542.246 \\
\hline
\end{tabular}

\section{Acknowledgment}

The authors are thankful to The Nelson Mandela African Institution of Science and Technology (NM-AIST) for sponsorship and the School of Computational and Communicational Science and Engineering at NM-AIST for providing necessary facilities to carry out this work.

\section{References}

[1] T. Ruiz-Anchondo, N. Flores-Holguín, and D. GlossmanMitnik, "Natural carotenoids as nanomaterial precursors for molecular photovoltaics: A computational DFT study", Molecules, vol. 15, no. 7, pp. 4490-4510, 2010.

[2] B. O'Regan and M. Grätzel, "A low-cost, high efficiency solar cell based on dye-sensitized colloidal $\mathrm{TiO}_{2}$ films", Nature, vol. 353, no. 6346, pp. 737-740, 1991.

[3] B. P. Kafle, B. R. Pokhrel, R. Gyawali, A. Kafle, T. M. Shrestha, R. Shrestha, and R. M. Adhikari, "Absorbance of natural and synthetic dyes: Prospect of application as sensitizers in dye sensitized solar cell", Absorbance Nat. Synth. Dye. Prospect Appl. as sensitizers Dye sensitized Sol. cell, vol. 5, no. 1, pp. 812, 2014.

[4] C. I. Oprea, B. Frecuş, B. F. Minaev and M. A. Gîrţu, "DFT study of electronic structure and optical properties of some Ruand Rh-based complexes for dye-sensitized solar cells", Mol. Phys. An International Journal at the Interface Between Chemistry and Physics, vol. 109, Issue 21, pp 2511-2523. 2011.
[5] F. De Angelis, S. Fantacci, and A. Selloni, "Alignment of the dye's molecular levels with the $\mathrm{TiO}_{2}$ band edges in dye-sensitized solar cells: a DFT-TDDFT study", Nanotechnology, vol. 19, no. 42, p. 424002, 2008.

[6] B. C. Mphande and A. Pogrebnoi "Impact of Extraction Methods upon Light Absorbance of Natural Organic Dyes for Dye Sensitized Solar Cells Application", J. Energy Nat. Resour., vol. 3, no. 3, p. 38, 2014.

[7] G. Goor, J. Glenneberg, and S. Jacobi, "Hydrogen Peroxide," in Ullmann's Encyclopedia of Industrial Chemistry, Wiley-VCH Verlag GmbH \& Co. KGaA, 2000.

[8] H. W. Liu, "Extraction and Isolation of Compounds from Herbal Medicines", in Traditional Herbal Medicine Research Methods, John Wiley \& Sons, Inc., 2011, pp. 81-138.

[9] M. B. Smith and J. March, March's advanced organic chemistry, vol. 6, no. 12. 2001.

[10] B. Huskinson, M. P. Marshak, C. Suh, S. Er, M. R. Gerhardt, C. J. Galvin, X. Chen, A. Aspuru-Guzik, R. G. Gordon, and M. J. Aziz, "A metal-free organic-inorganic aqueous flow battery", Nature, vol. 505, no. 7482, pp. 195-198, Jan. 2014.

[11] D. E. Wheeler, J. H. Rodriguez, and J. K. McCusker, "Density Functional Theory Analysis of Electronic Structure Variations across the Orthoquinone/Semiquinone/Catechol Redox Series", J. Phys. Chem. A, vol. 103, no. 31, pp. 6282-6282, 1999.

[12] M. Oftadeh and B. Barati, "Theoretical study of 1 and 4 benzoquinone and difluoro derivatives of benzoquinone on zinc oxide nano particles by DFT method", vol. 1, pp. 284-287, 2011. 
[13] Priyanka Singh, N. P. Singh, R. A Yadav "Vibrational study on the molecular structure of 1,4-naphthoquinone and 2-methyl-1,4-naphthoquinone and their radical anions by using density functional theory", J. Chem. Pharm. Res., vol. 2, no. 3, pp. 199-224, 2010.

[14] M. Ahmed and Z. H. Khan, "Electronic absorption spectra of benzoquinone and its hydroxy substituents and effect of solvents on their spectra", Spectrochim. Acta - Part A Mol. Biomol. Spectrosc., vol. 56, no. 5, pp. 965-981, 2000.

[15] A. Kuboyama, S. Matsuzaki, H. Takagi, and H. Arano "Studies of the $\pi-\pi^{*}$ Absorption Bands of p-Quinones and o-Benzoquinone", Natl. Chem. Lab. Ind. Shinya, Tokyo, vol. 47 (7), Shibuya-ku, Tokyo 151, pp. 1604-1607, 1974.

[16] A. A Granovsky, Firefly version 8.1.0, www http://classic.chem.msu.su/gran/firefly/index.html

[17] M. W. Schmidt, K. K. Baldridge, J. A. Boatz, S. T. Elbert, M. S. Gordon, J. H. Jensen, S. Koseki, N. Matsunaga, K. A. Nguyen, S. Su, T. L. Windus, M. Dupuis, J. A. Montgomery. "General Atomic and Molecular Electronic Structure System", J. Comput. Chem.; vol. 14, pp. 1347-1363; 1993. doi:10.1002/jcc. 540141112.

[18] R. G. Parr and W. Yang, Density-Functional Theory of Atoms and Molecules. New York: Oxford University Press, 1989.

[19] E. Rung and E. K. U. Gross, "Density-Functional Theory for Time-Dependent Systems”, Phys. Rev. Lett, vol. 52, no. 12, pp. 997-1000, 1984.

[20] K. L. Tokarev, "OpenThermo", v.1.0 Beta 1 (C) ed. http://openthermo.software.informer.com/, 2007-2009.

[21] HyperChem ${ }^{(\mathrm{TM})}$, H., Inc., $1115 \mathrm{NW}$ 4th Street, Gainesville, Florida 32601, USA.

[22] G. A Zhurko, D. A. Zhurko, "Chemcraft. Version 1.7 (build 132)." http://www.chemcraftprog.com.

[23] N. W. Larsen, "Microwave spectra of the six mono-13C-substituted phenols and of some monodeuterated species of phenol. Complete substitution structure and absolute dipole moment", J. Mol. Struct., vol. 51, pp. 175-190, 1979.

[24] A. L. Macdonald and J. J. Trotter. Chem. Soc., Perkin Trans. vol. 2 p. 476, 1973.

[25] K. Hagen, K. Hedberg, "Reinvestigation of the molecular structure of gaseous p-benzoquinone by electron diffraction", $J$. Chem. Phys., vol. 59, no. 1, p. 158, 1973.

[26] C. G. Zhan and S. Iwata, "Ab initio MO and density functional studies on the vibrational spectra of 1,4-benzoquinone, and its anion and dianion", Chem. Phys., vol. 230, no. 1, pp. 45-56, 1998.

[27] J. Gaultier and C Hauw, "Structures des dérivés 2 et 2,3 de la naphtoquinone-1,4. IV. Le phtiocol - antagonisme par analogie structurale", Acta Cryst, vol. 18, pp. 179-183, 1965.

[28] A. Prakash, "Refinement of the crystal structure of anthraquinone", Acta Crystallogr., vol. 22, no. 3, pp. 439-440, Mar. 1967.
[29] S. N. Ketker, M. Kelley, M. Fink, and R. C. Ivey, "On an electron diffraction study of the structures of anthraquinone and anthracene", J. Mol. Struct., vol. 77, no. 1-2, pp. 127-138, Nov. 1981.

[30] J. C. Evans, "The vibrational spectra of phenol and phenol-OD", Spectrochim. Acta, vol. 16, no. 11-12, pp. 1382 1392,1960

[31] J. H. S. Green, "The Thermodynamic Properties of Organic Oxygen Compounds. Part II. Vibrational Assignment and Calculated Thermodynamic Properties of Phenol", J. Chem. Soc., no. 2236, pp. 2236-2241, 1960.

[32] NIST Mass Spec Data Center, S.E. Stein, director, "Infrared Spectra", NIST Chemistry WebBook, NIST Standard Reference Database Number 69, Eds. P. J. Linstrom and W. G. Mallard, National Institute of Standards and Technology, Gaithersburg MD, 20899, http://webbook.nist.gov, (retrieved August 13, 2015).

[33] E. D. Becker and A. Charneye, "Molecular vibrations of quinones. iv. Raman spectra of p-benzoquinone and its centrosymmetrically substituted isotopic derivatives and assignment of observed frequencies", J. Chem Phys, vol. 42, pp. 942-949, 1965.

[34] J. C. Dearden and W. F Forbes, "Light absorption studies part XIV. The ultraviolet absorption spectra of phenols", Can. J. Chem. vol. 37, pp. 1294-1304, 1959.

[35] S. Nagakura, A. Kuboyama, J. Am. Chem. Soc., 76, 1003, 1954.

[36] J. Y. Kim. and Y. S. Kim, "Phenoxazine-Based Dyes with Dual Electron Donating Moiety for Organic Dye-Sensitized Solar Cells", Mol. Cryst. Liq. Cryst., vol. 551, pp. 138-146, 2011.

[37] V. Talrose, A.N. Yermakov, A.A. Usov, A.A. Goncharova, A.N. Leskin, N.A. Messineva, N.V. Trusova, M.V. Efimkina, "UV/Visible Spectra" NIST Chemistry WebBook, NIST Standard Reference Database Number 69, Eds. P.J. Linstrom and W.G. Mallard, National Institute of Standards and Technology, Gaithersburg MD, 20899, http://webbook.nist.gov, (retrieved August 13, 2015).

[38] M. Martynoff, "Note de laboratoire: Spectres d'absorption de quelques p-quinones", Bull. Soc. Chim. Fr, vol. 16, pp. 258-261, 1949.

[39] J. Rigaudy, G. Cauquis, G. Izoret, "Etudes sur les amino-9 anthracenes. I. Autoxydation, oxydation et action du peroxyde de benzoyle", Bull. Soc. Chim. Fr., pp. 1842-1849, 1961.

[40] L. M. Peter, "Characterization and Modeling of Dye-Sensitized Solar Cells", J. Phys. Chem. C, 111(18), pp 6601-6612, 2007.

[41] S. A. Kudchadker, "Ideal gas thermodynamic properties of phenol and cresols", J. Phys. Chem. Ref. Data, vol. 7, pp. 417423, 1978.

[42] E. D. Becker, "Molecular vibrations of quinones. VI. A vibrational assignment for p-benzoquinone and six isotopic derivatives. Thermodynamic functions of p-benzoquinone", $J$. Chem. Phys, vol. 42, pp. 942-949, 1965.

[43] S. N. Singh, "Thermodynamic properties of some condensed ring quinones", Indian J. Pure Appl. Phys, vol. 7, pp. 52-53, 1969. 